flexibility of the British system of social administration gave them their chance, particularly in the handling of 'problem' children encountered by evacuation authorities. Much of the work now done by the Child Care Service is built on foundations laid at this time. It is therefore to be hoped that Prof. Titmuss will continue his task and attempt to apply the lessons he has drawn from the social history of the War to contemporary conditions.

The voluntary associations, which contributed so efficiently and perhaps even decisively to the solution of the social problems of the time, are now gravely weakened as the result of the Government's taxation policy. The structure of local government, which again contributed so much, is also seriously undermined. Are the new national agencies, such as the National Assistance Board and the Regional Hospitals Boards, able to take their place in another emergency that may arise in the near future? Are they prepared to pay adequate attention to the work of the social scientist, and place sufficient reliance on the skills of the professional social worker ? Prof. Titmuss should give us an answer to this disturbing, but critically important, question.

T. S. SIMEY

\section{PLANT PHYSIOLOGY FOR STUDENTS}

An Introduction to the Principles of Plant Physiology

By Prof. Walter Stiles. Second edition, revised. Pp. $x+701+5$ plates. (London: Methuen and Co., Ltd., 1950.) 60s, net.

FOR fourteen years the first edition of this text-

book has been familiar to students all over the English-speaking world. It needs no introduction to botanists, and it is the pleasant first duty of a reviewer to welcome a second edition, and to commend it to such students as can afford to buy it, and to all who teach plant physiology, whether they can afford to buy it or not. For Prof. Walter Stiles has over many years earned a reputation for accuracy in recording facts, impartiality in presenting controversial matters, and a lucidity of expression rare among botanists.

The new edition is some eighty-five pages longer than the old, but it retains the latter's balance. All specialists, of course, will find the appropriate shortcomings : there will be some readers who are disappointed that such topics as respiration and photosynthesis are not given more up-to-date treatment, and other readers will cavil at the condensed accounts of anomalous osmosis and the physiology of reproduction. But discerning readers will remember that the book is the work of one man, and that it gains in homogeneity much more than it loses in detail-and of all subjects, plant physiology is the most in need of homogeneity. Indeed, if one has any eriticism to offer to Prof. Stiles, it is in respect of the title of his book; for plant physiology has no principles. It cannot be presented even with the coherence of $a$ fairy story, as the vascular cryptogams can, or with the reassuring monotony of a telephone directory, as the angiosperms sometimes are presented. Plant physiology is an unrelated succession of solutions to bialogical problems by chemical and physical techniques. It cannot, therefore, be summarized in a systematic way, and it cannot, therefore, ever make easy reading. An additional difficulty in presenting plant physiology is that the subject is in transition from a qualitative and descriptive phase to a quantitative and analytical one. Not only the older techniques, but also even the older philosophical approaches to plant physiology, are no longer adequate. Prof. Stiles does not evade these difficulties. He uses numerical data whenever possible. $\mathrm{He}$ eschews generalizations even when it would be tempting to make them; and he does not invest plant physiology with a misleading and attractive coherence.

A reading of Prof. Stiles's book does provoke the question as to how plant physiologists should be trained. To think usefully about respiration or nitrogen metabolism requires the discipline of an honours degree in chemistry. To think usefully about water relations and growth requires the disciplines of an honours degree in physics and mathematics. Further, if these topics are to be understood in their biological context, and not merely as branches of chemistry or physics, there can be no diminution in the amount of morphology or anatomy to be learnt by a plant physiologist: he must in addition have the discipline of an honours degree in botany. At present, most plant physiologists are botanists who have taught themselves chemistry, or chemists who have taught themselves botany. Perhaps the time has come to divide honours botany courses into non-experimental (with subsidiary zoology and geology) and experimental (with subsidiary chemistry and physics). It would mean that the student who graduated in experimental botany would no longer be familiar with the evidences of phylogenetic inertia in the pteridosperms; but if, instead, he knew enough chemistry to appreciate thoroughly Prof. Stiles's chapters on metabolism, the loss might be bearable.

E. Ashisy

\section{HORTICULTURAL HISTORY OF THE UNITED STATES}

A History of Horticulture in America to 1860 By U. P. Hedrick. Pp. xiii $+551+32$ plates. (New York and London: Oxford University Press, 1950.) 45s. net.

THE history of horticulture, as compared with the history of, say, botany, has been strangely neglected. It is true that the development of gardens and gardening has been well documented in many countries, but the making of a garden, though it may be the end, is not the whole of horticulture. Before a plant can take its place in a row of vegetables or in a well thought-out scheme of a landscape architect, it must have been collected from the wild, worked on, perhaps for years, by the plant breeder or selector, propagated and increased in a nursery, and catalogued, advertised and sold by the horticultural trade, wholesale and retail. This 'pre-garden' aspect of horticulture is set against a much wider background than is the art of gardening itself and offers a fascinating opportunity for the historian. This opportunity, as regards horticulture in the United States before 1860, has been taken with characteristic thoroughness and skill by Mr. U. P. Hedrick in his "latest volume"-a phrase, in the case of Mr. Hedrick, with more than its usual significance, for he has already, in a long succession of admirable books, made a most valuable contribution to horticultural literature. As horticulturist, and later director, of 